\title{
Behavior of structural concrete frames with hybrid reinforcement under cyclic loading
}

\author{
Asmaa Sobhy, Louay Aboul Nour, Hilal Hassan \\ Zagazig University, Egypt \\ asmaasobhyamer@eng.zu.edu.eg, http://orcid.org/0000-0002-3660-4725 \\ lonayabdelrazek@yahoo.com, bttp://orcid.org/0000-0003-1557-0244 \\ bilalcivil@yahoo.com@yahoo.com,bttp://orcid.org/0000-0001-5486-5497
}

\author{
Alaa El-Sisi \\ University of Missouri, USA; on research leave from Zagazig University, Egypt \\ ElsisiAE@missouri.edu, bttp://orcid.org/0000-0001-8190-6100
}

ABSTRACT. A substantial amount of work was carried out on the use of fiberreinforced polymer (FRP) in reinforced concrete structural elements, which demonstrated considerable inelasticity or deformity through monotonic and cyclic loads. Even so, the action of FRP bars in reinforced concrete columns and frame structures has not yet been studied during reversed cyclic loading. In this research, reversed cyclic loading was applied on three beam-column joint models using the finite element method with ANSYS software. The first model was for a joint designed with steel rebar for both the longitudinal and transversal reinforcement. Glass fiber reinforced polymer (GFRP) rebar was used in the second joint model for the longitudinal reinforcement with steel transversal reinforcement. The third joint model was designed with hybrid steel/GFRP reinforcement for the longitudinal reinforcement and steel transversal reinforcement. The performance of the three models under reversed cyclic loading, such as load vs. story drift and energy dissipation capacity, were compared. The GFRP-reinforced model displayed a predominantly elastic behavior up to failure. Although its energy dissipation was lower, its performance in terms of total story drift demand was satisfactory.

KEYwORDS. GFRP; Hybrid reinforcement; Cyclic loading; Beam-column joint; Frames.

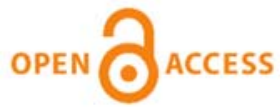

Citation: Sobhy, A., Aboul Nour, L., Hassan, H., El-Sisi, A., Behavior of Structural Concrete Frames with Hybrid Reinforcement under Cyclic Loading, Frattura ed Integrità Strutturale, 57 (2021) 70-81.

Received: 05.04 .2021 Accepted: 12.05 .2021 Published: 01.07.2021

Copyright: (C) 2021 This is an open access article under the terms of the CC-BY 4.0, which permits unrestricted use, distribution, and reproduction in any medium, provided the original author and source are credited. 


\section{INTRODUCTION}

7 he primary reason for the collapse of the reinforced concrete (RC) buildings is steel corrosion, which requires multimillion annual maintenance costs worldwide. Furthermore, the use of modern equipment with magnetic interferometers, such as in medical radiology buildings, requires a non-magnetic structure without steel reinforcement. This led to growing interest in the use of the non-magnetic and corrosion-resistant fiber-reinforced polymer (FRP) reinforcement [1,2].

In the last decade, substantial efforts were made to extend FRP composite materials to the construction sector, and, finally, structural uses of composite materials have started to arise in civil structures.

FRP composite materials are being used as interior and exterior reinforcements in the field of structural engineering due to the high tensile strength to weight ratio, higher stiffness, lower density, chemical attack resistance, and other properties [38].

Significant research activities in recent years have demonstrated that FRP materials can be used successfully to strengthen reinforced concrete structures [9-13]. High-tensile fiber stiffeners, such as carbon, glass, aramid, and basalt, are integrated into polymeric arrays and made in different shapes such as rods, grids, and tubes [3]. The characteristics of lightweight, high strength, acceptable fatigue resistance, and superior corrosion resistance also make FRP composites a major source of use as construction material or reinforcement in civil engineering [14-16]. FRP composite materials showed poorer elasticity and lowered bonding with concrete compared to traditional steel reinforcement. A bonding of FRP with concrete is being strengthened with mechanical anchorages such as sanding and surface deformation; however, particularly in structures subjected to dynamic loading, its poor ductility persists as a major problem [1].

In recent decades, most research works were conducted on the concrete beam behavior and column structures with FRP rebar reinforcement. Still, little research was conducted on FRP reinforced concrete frame structures, particularly subjected to seismic loading.

Nehdi and Said studied the experimental behavior of RC frames reinforced with hybrid bars under cyclic loading [17]. The three beam-column joints were tested under cyclic loading and were reinforced with steel, Glass fiber reinforced polymer (GFRP), and hybrid GFRP/steel. The cross-section of the beam of the hybrid joint had three steel bars and three GFRP bars as longitudinal bottom and top reinforcements, respectively. It was found that the GFRP joint significantly displayed lower plastic characteristics. This led to poorer dissipation of energy compared to hybrid and steel joints. The hybrid joint has shown lower stiffness than the steel joint and higher stiffness than the GFRP joint [17].

The cyclic behavior of beam-column joints of reinforced concrete with GFRP bars and stirrups was investigated [18]. The case study consisted of five full-scale RC beam-column joints with T-shape, which were experimented under cyclic load. The key parameters analyzed are the transversal and longitudinal reinforcement ratios and types. The study has indicated that the reinforced joints with GFRP could reach a $4.0 \%$ drift percentage without suffering noteworthy damage. In addition, it was concluded that increasing the beam reinforcement ratio can enhance the ability of the joint to dissipate the seismic energy through utilizing the inelastic behavior of concrete.

Ghomi and El-Salakawy $[19,20]$ investigated the seismic behavior of the RC beam-column joints with GFRP reinforcement. It was inferred that the axial load level of the columns greatly affects the earthquake's behavior of the RC beam-column joints with GFRP reinforcement. Structural elements are sensitive to brittle collapse in this region and are unable to achieve extreme strength capability. In comparison, the rising axial load of columns in steel-RC samples did not show a substantial effect on the envelope of lateral load drift relation of the joints [19,20]. Furthermore, M. Hasaballa and E. El-Salakawy [21] analyzed the external shear strength of the RC beam-column joint with GFRP reinforcement, and the results indicated that the overall joint shear stress must be reduced to avoid joint damage [21].

In recent decades, there has been increasing attention in comparison between FRP-RC and steel-RC structures. However, research in this field was usually limited to some column and beam tests. Most of the recently accepted design standards for reinforced concrete elements with FRP are not completed, and detailed seismic provisions are not always included.

A study is also required to investigate the FRP-RC frame performance under cyclic reversed loading in order to create the foundation for future design code requirements for FRP reinforced concrete for seismic areas.

In this research, the beam-column joints reinforced with steel, GFRP, and hybrid steel/GFRP rebars were studied numerically by using ANSYS finite element code [22]. The joints were analyzed under cyclic reversed loading. Comparison and discussion of their performance, including energy dissipation and load-story drift envelope, were performed. 


\section{NUMERICAL ANALYSIS AND VERIFICATION MODEL}

7 he finite element method (FEM) is a numerical method to solve integral or differential equations and also to obtain approximate solutions for a variety of engineering problems [23]. In this research, 3D finite element modeling was conducted using ANSYS 18.2 software. This section presents the analytical approach and assumptions used in the analysis and the elements and material models selected from the software library. Element SOLID 65 is used for the simulation of concrete. SOLID 65 is an eight nodes element, where each node has three translation nodal degrees of freedom in the $\mathrm{x}, \mathrm{y}$, and $\mathrm{z}$ directions. The Solid 65 element can estimate cracking in three principal directions, plastic deformation, creep, and crushing concrete. Element LINK 180 was used for the simulation of steel and GFRP rebar. The element is a uniaxial compression-tension element with three degrees of freedom at each node; the translations in the nodal directions $\mathrm{x}, \mathrm{y}$, and $\mathrm{z}$. Element SOLID 185 is used for the simulation of loading and bearing plates. This element is characterized by eight nodes with three translations nodal degrees of freedom in the nodal cartesian directions $x, y$, and $z$ [7,24-28].

An experimentally tested beam-column joint was used from literature to validate numerical analysis via ANSYS software [29]. The dimension of the tested joint is shown in Fig. 1. The flexural reinforcement of the beam was five longitudinal rebars with a diameter of $19.5 \mathrm{~mm}$ top and bottom and rectangular stirrups with a bar diameter of $11.3 \mathrm{~mm}$ every $100 \mathrm{~mm}$. The reinforcement steel of the column was eight longitudinal rebars with a bar diameter of $15.9 \mathrm{~mm}$ and rectangular stirrups with $11.3 \mathrm{~mm}$ diameter every $90 \mathrm{~mm}$.

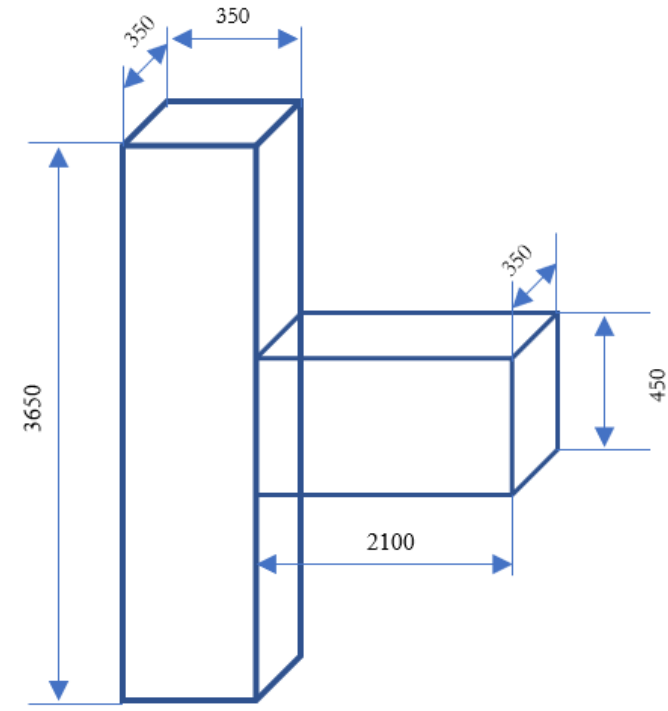

a) Joint Geometry
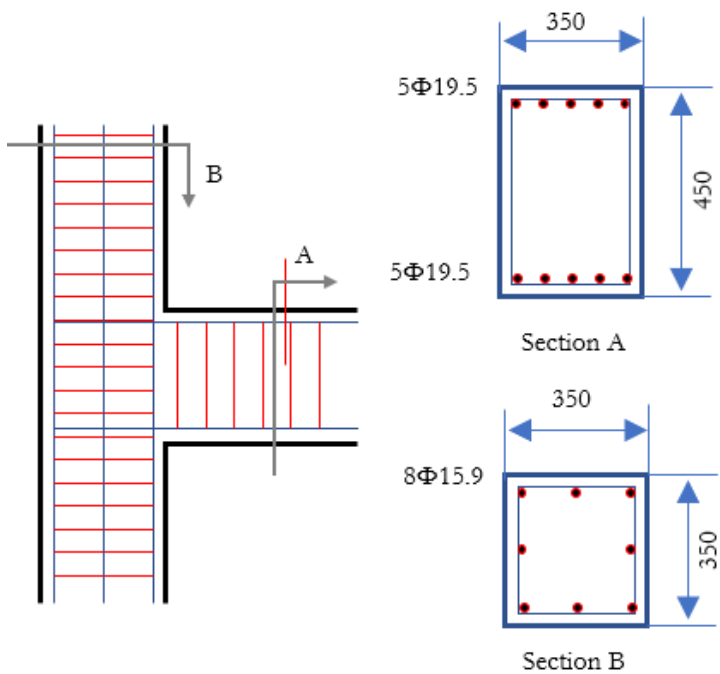

b) Joint Reinforcement

Figure 1: Details of tested beam-column joint (dimensions in $\mathrm{mm}$ and $\Phi$ denotes the rebar diameter).

The steel reinforcement yield strength $(f y)$ was equal to $400 \mathrm{MPa}$, and the concrete compressive strength $(f c)$ was equal to 32.4 MPa. The joint specimen was loaded under reversed cyclic load, where two phases exist in the loading process. A loadcontrolled mode was carried out in the first phase, while a displacement-controlled mode was employed in the second phase. The cyclic reversed load, as seen in Fig. 2, has been applied to the beam end top surface, the column head has been subjected to an axial force with a constant magnitude of $670 \mathrm{kN}$ and continued constant in all loading cycles. Restraints against both vertical and horizontal displacements were applied to the two ends of the column; meanwhile, their rotations were permitted (hinged boundary conditions).

The beam-column joint was modeled by using the ANSYS program, as shown in Fig. 3. The hysteretic diagram of the model is shown in Fig. 4a, and a comparison between the numerical and experimental results is shown in Fig. 4b. It can be concluded that analysis using the ANSYS FE code obtained the same trend of the experimental work results with good accuracy as the percentage difference between results was $10 \%$. 


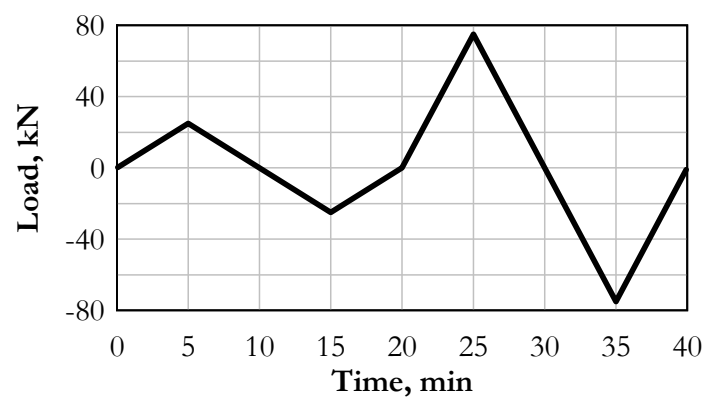

a) First phase load-controlled load.

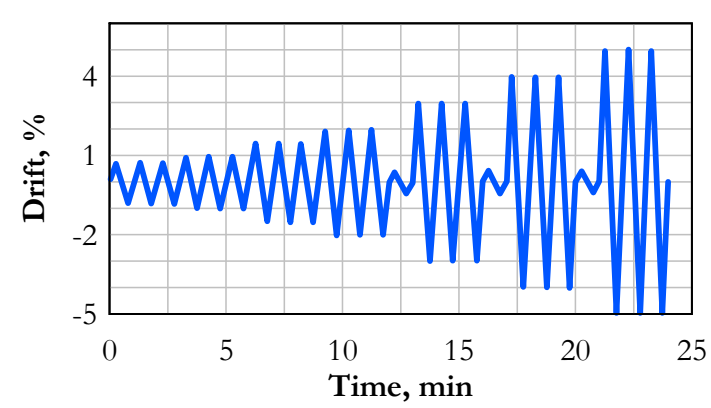

b) Second phase displacement-controlled load.

Figure 2: Load history for the reversed cyclic load [29].

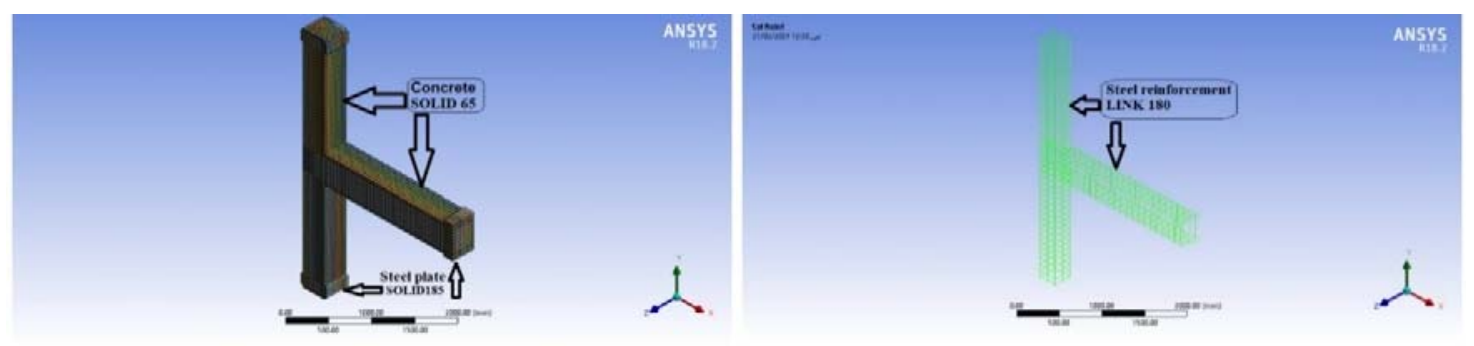

Figure 3: Finite element model details of the studied joint.
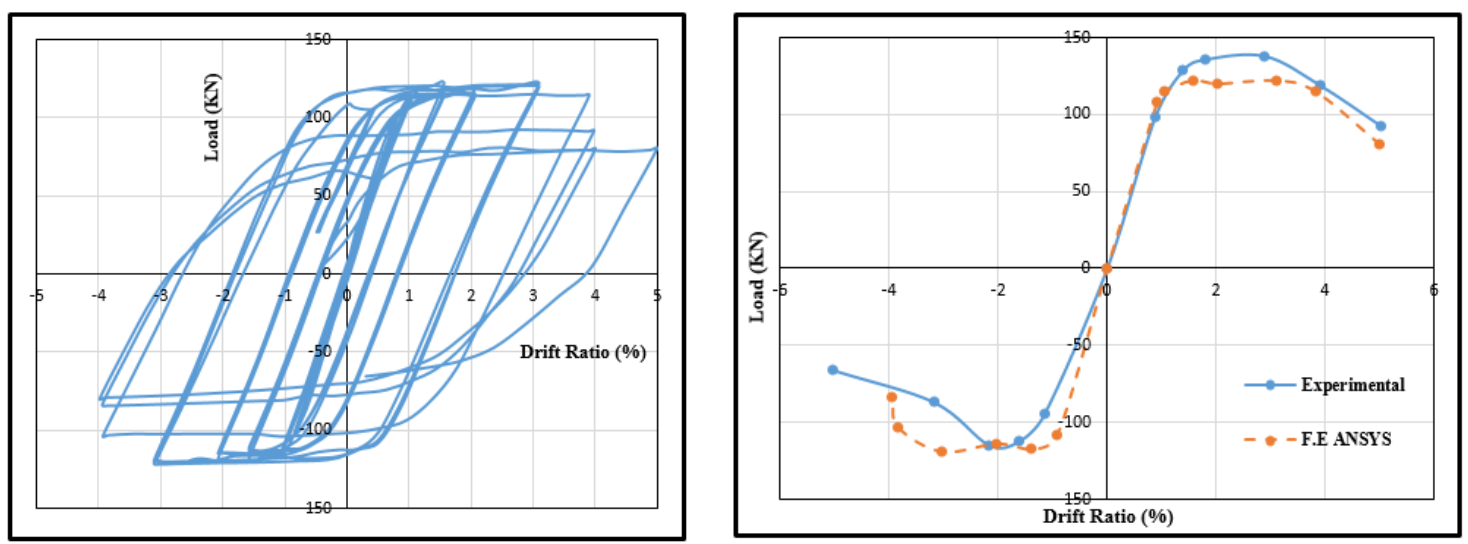

Figure 4: FE model results; a) Load-story drift relationship of FE model and b) FE VS Experimental Load-drift envelope.

\section{PARAMETRic StUdy}

7 hree models of beam-column joint have analyzed under reversed cyclic loading by finite element method using ANSYS software. The numerical model has the same characteristics as the verification model, but there are some differences, such as the model dimension, reinforcement, and the load history for the reversed cyclic load. Figs. 5a shows the overall reinforcement and dimensions of the three models where the column height was $3000 \mathrm{~mm}$ with a crosssection of $300 \times 400 \mathrm{~mm}$. The control beam sample was $2300 \mathrm{~mm}$ with a $300 \times 400 \mathrm{~mm}$ cross-section. The first model (S1) was reinforced with steel stirrups and longitudinal rebar. The second model (G1) was reinforced with steel stirrups and GFRP longitudinal rebar. Hybrid reinforcements and steel stirrups were used in the third model (H1). The reinforcement of the three models is shown in Fig. $5 \mathrm{~b}$ to $5 \mathrm{~d}$. 


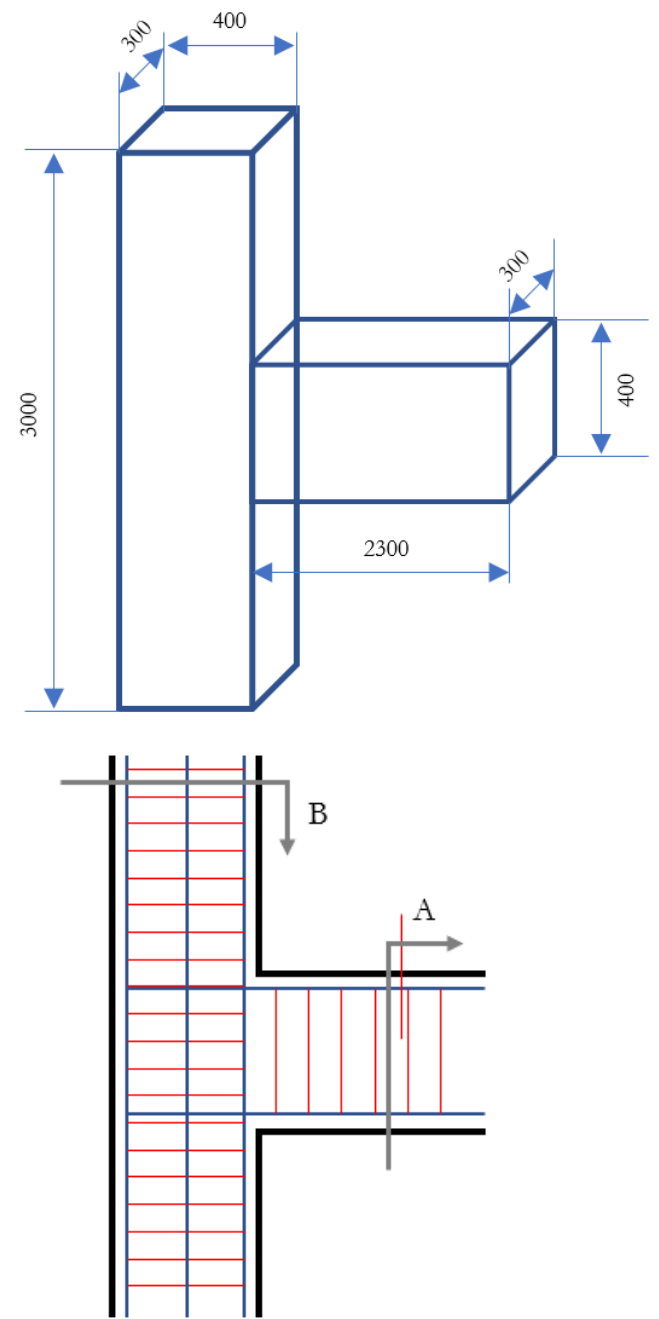

a) Beam dimension and reinforcement.

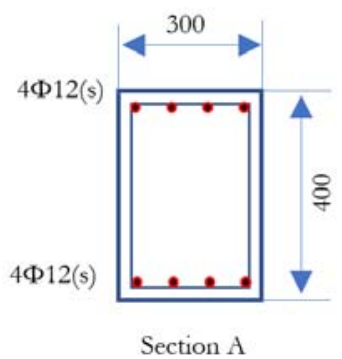

b) Reinforcement of S1.

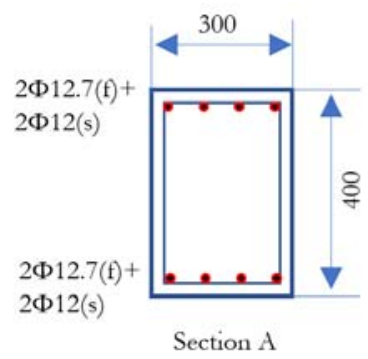

c) Reinforcement of H1.
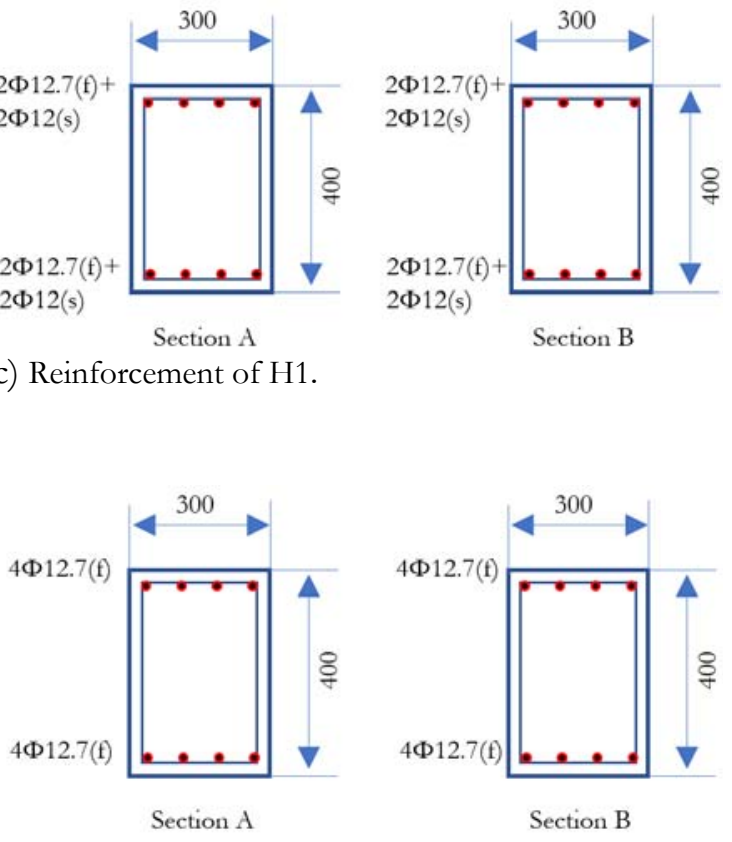

d) Reinforcement of G1.

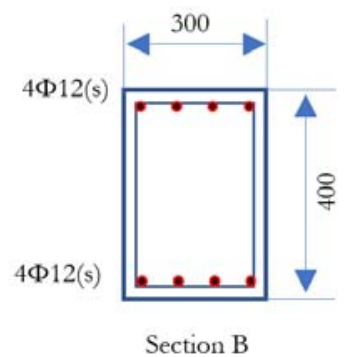

Section B
Section B

Section B

Figure 5: Geometric and reinforcement details of beam-column joints; a) Joint Geometry and reinforcement, b) Reinforcement of S1, c) Reinforcement of H1; and d) Reinforcement of G1. (dimensions in mm, s denotes steel rebar, and f denotes GFRP rebar).

The material model used for concrete is associated with the element SOLID 65. The model is defined by the concrete compressive strength, tension strength, shear stiffness for opened and closed concrete crack, and the residual stiffness after failure. This model simulates the elastic damage of concrete, but it can also include the effect of the plasticity by adding multilinear isotopic hardening relation to the material definition. At each element integration point, if the compressive failure criteria are achieved, the element loses its stiffness contribution at this point. Bilinear isotropic hardening plasticity model was used for the steel. These model characteristics are the elastic constants, the yield stress, and the plastic tangent modulus. The mechanical properties and plasticity parameters of the materials used in the beam-column joint models according to ECP (201), ECP (208), ISIS Canada, and ACI 440.R1.06 [30-33], are shown in the following Tab. 1.

\section{Modeling and Meshing Methodology}

The solid element SOLID 65 was used to model the concrete. Before cracking or crushing, the material of concrete was modeled to behave initially isotropic. Eight integration points exist at each element at which crushing and cracking checks are executed. Crushing or cracking occurs once the principal stresses of any element exceed the compressive or tensile concrete strength. The damaged regions are shaped perpendicular to the direction of the related principal stress. Local redistribution of the stresses then occurs. Therefore, an iterative solution is needed to handle the element nonlinearity. A LINK 180 element was used to model the steel GFRP reinforcement. Generally, steel is very uniform, unlike concrete and the specification of a single stress-strain relation is satisfactory to be defined numerically. The solid element SOLID 185 
was used to model the loading and bearing plates. Finite element analysis requires meshing of the model; hence the models are divided into many small elements. Convergency analysis was performed in order to balance the results accuracy, the solution time, and storage file size. After several trials, it was found that meshing the model with an element size of $50 \mathrm{x} 50$ x $50 \mathrm{~mm}$ has obtained good results with 3D concrete elements SOLID 65 and hexagonal sweep mesh option. The finite element model of beam and column is shown in Fig. 6.

\begin{tabular}{|c|c|c|c|c|}
\hline Material & Property & Notation & \multicolumn{2}{|c|}{ Value } \\
\hline \multirow{4}{*}{ Concrete } & Elastic modulus & $E c$ & \multicolumn{2}{|c|}{$28125 \mathrm{MPa}$} \\
\hline & Poisson's ratio & $v$ & \multicolumn{2}{|c|}{0.25} \\
\hline & $\begin{array}{l}\text { Unconfined } \\
\text { compressive } \\
\text { strength }\end{array}$ & $f c$ & \multicolumn{2}{|c|}{$30.00 \mathrm{MPa}$} \\
\hline & Tensile strength & $f t$ & \multicolumn{2}{|c|}{$2.91 \mathrm{MPa}$} \\
\hline \multirow{4}{*}{$\begin{array}{c}\text { Reinforcement } \\
\text { steel }\end{array}$} & Elastic modulus & $E_{\mathrm{s}}$ & \multicolumn{2}{|c|}{$200 \mathrm{GPa}$} \\
\hline & Poisson's ratio & $v$ & \multicolumn{2}{|c|}{0.2} \\
\hline & \multirow[b]{2}{*}{ Yield strength } & \multirow[b]{2}{*}{ fy } & Longitudinal & Stirrup \\
\hline & & & $400 \mathrm{MPa}$ & $280 \mathrm{MPa}$ \\
\hline \multirow{3}{*}{ GFRP } & Elastic modulus & $E \mathrm{f}$ & \multicolumn{2}{|c|}{$43 \mathrm{GPa}$} \\
\hline & & & \multirow{2}{*}{\multicolumn{2}{|c|}{$765 \mathrm{MPa}$}} \\
\hline & Ultimate Strength & $f_{\mathrm{fu}}$ & & \\
\hline
\end{tabular}

Table 1: Mechanical characteristics of concrete, steel reinforcement and GFRP reinforcing bars materials.

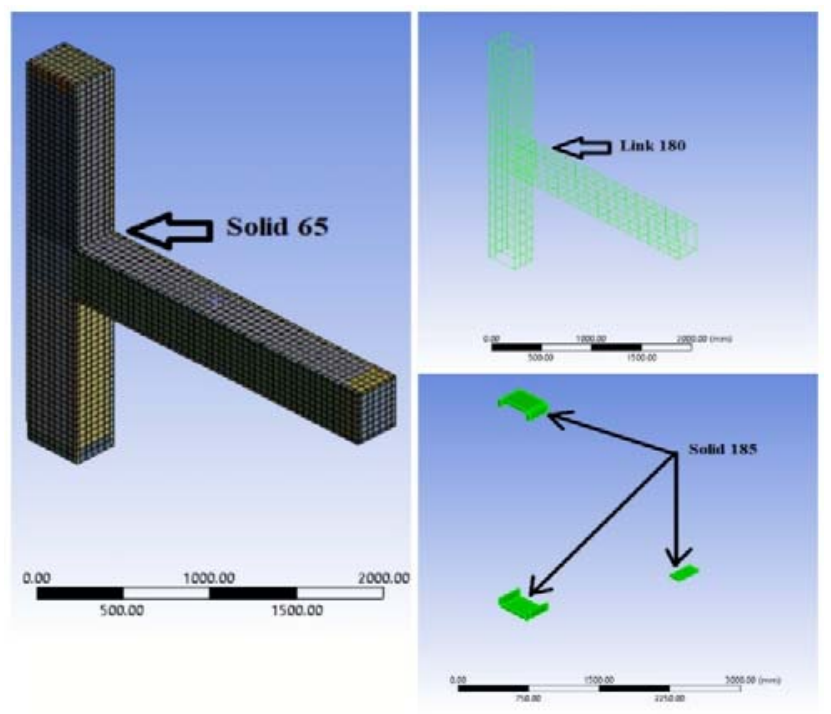

Figure 6: Components of the FE model.

The concrete was connected to the reinforcement steel or FRP bars in ANSYS using bonded contact. The concrete was bound to the loading and bearing plates by merging the coincide nodes at the interface between them. To simulate hinged support condition at the lower column end and roller support condition at the upper ends of the column, restraints were applied, as shown in Fig. 7a. 


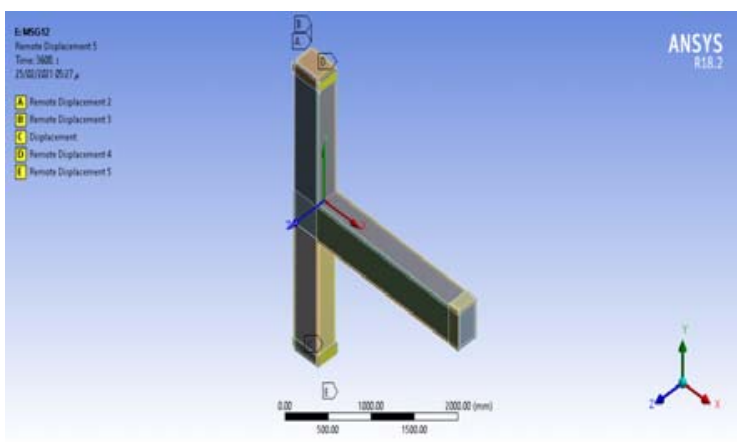

a) Boundary Conditions

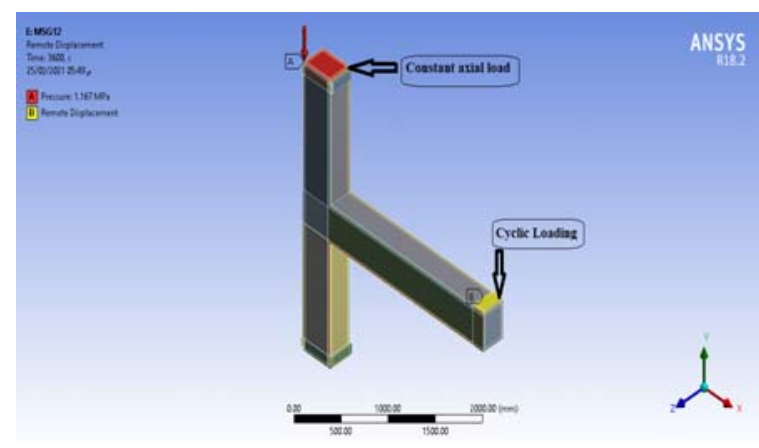

b) The Applied Loads

Figure 7: Boundary conditions and the applied loads of the FE model.

Beam-column joint models have been analyzed under reversed cyclic load. As seen in Fig. 7b, the cyclic reversed load has applied to the upper end of the beam, while the column head has been subjected to a constant axial load with a magnitude of $140 \mathrm{kN}$, which was maintained constant in all loading cycles. The history of the reversed cyclic load was used similar to the experimental work performed by Paknejadi, [34], as seen in Fig. 8.

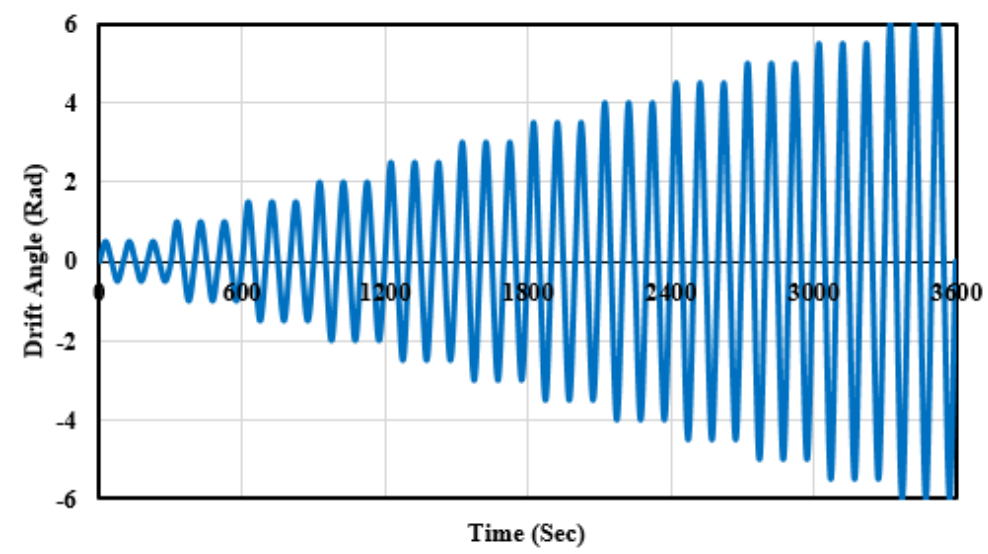

Figure 8: Load history for the reversed cyclic load.

\section{RESUlts AND Discussion}

$\mathrm{I}$

$\mathrm{n}$ this section, the results of the three cases under investigation will be discussed. Results such as hysteretic relations will be presented. The deformed shapes of the models at failure are shown in Fig. 9.

\section{Steel-Reinforced Model (S1)}

The hysteretic diagram of the steel model S1 is shown in Fig. 10. The diagram displays that model achieved a maximum drift ratio of $5.35 \%$ with a maximum load of $51 \mathrm{kN}$ in a positive direction. Ultimate capacity was measured to drift ratios in both of the positive and negative directions of $5.53 \%$ and $5 \%$, respectively. After completion of the $4.5 \%$ drift cyclic load step, the model failure happened at a drift ratio of $5 \%$ in a negative direction. The FE analysis was promptly terminated without having completed the $5 \%$ drift ratio loop. Failure mode was the cracking of the concrete in the sections of the beam near the face of the column, as shown in Fig. 9a. The elements in this zone were highly distorted due to the loss of stiffness caused by ye concrete cracking. A significant loss in the shear capacity of the beam was evaluated, which caused a large movement of the beam part near the joint. In addition, due to the plastic deformation of steel reinforcement, a shifting was observed in the cycles, as seen in Fig. 10. 


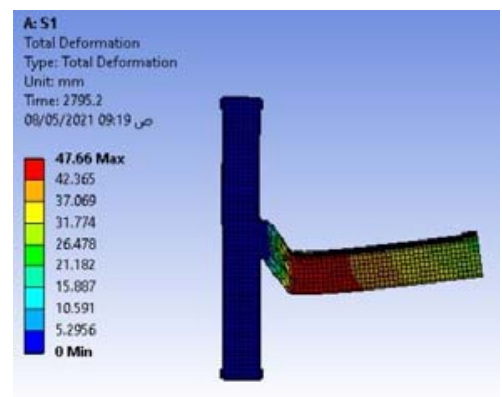

a) Model S1

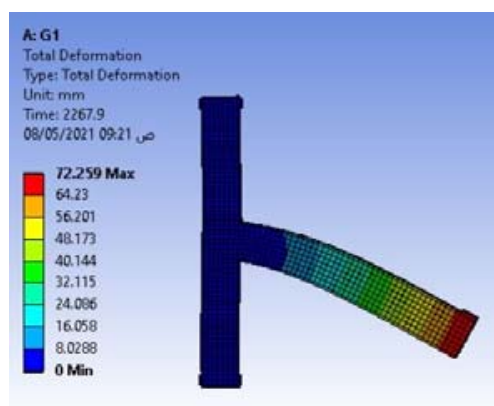

b) Model G1

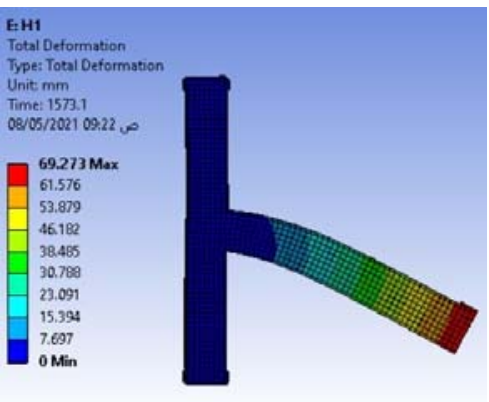

c) Model H1

Figure 9: Total deformation of the FE models.

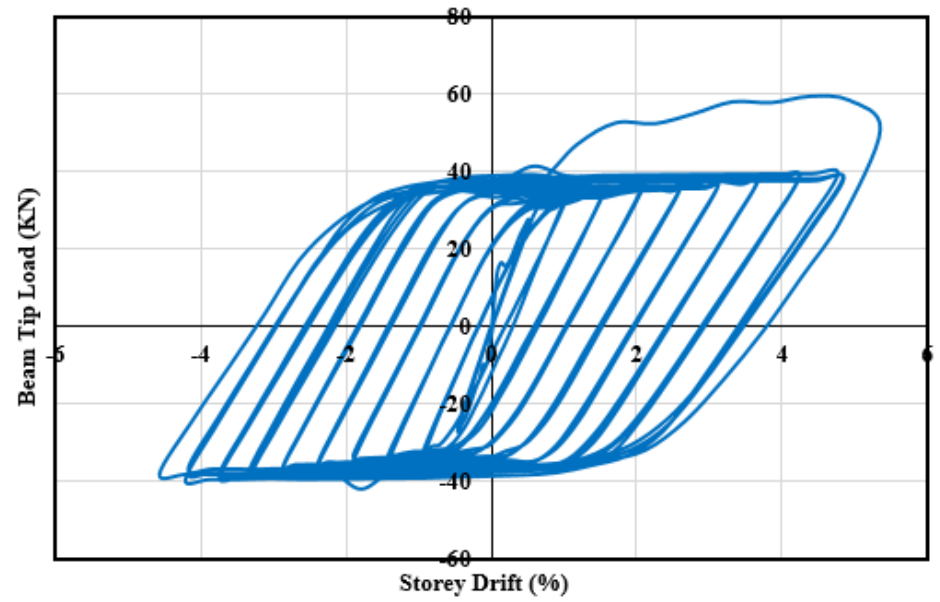

Figure 10: Load-story drift relationship of steel model S1.

\section{GFRP-Reinforced Model (G1)}

The hysteretic diagram of the GFRP model G1 is shown in Fig. 11. Linear elastic performance was demonstrated in the model until failure. Model G1 achieved a maximum drift ratio of $4.21 \%$ with a maximum load of $44.7 \mathrm{kN}$ in a positive direction, as displayed in the hysteretic diagram. Ultimate capacity was measured to drift ratios in both of the positive and negative directions of $4.21 \%$ and $3.19 \%$, respectively. After completion of the $3.5 \%$ drift ratio-cyclic load step, the failure happened at $4 \%$ drift ratio in a negative direction. The FE analysis was promptly terminated without completing the $4 \%$ drift ratio loop. Failure mode was the cracking of the concrete in the sections of the beam close to the face of the column, and diagonal shear cracks appeared in the joint area, as seen in Fig. 9b.

The concrete elements in this zone were subjected to excessive crushing and cracking, while the GFRP rebar remained in the elastic range. Due to the low deformation of the GFRP rebar and the absence of the plastic deformation, no significant shear failure happened to like the case of S1. In addition, no shifting was observed in the cycles, as seen in Fig. 11.

\section{Hybrid-Reinforced Model (H1)}

The hysteretic diagram of the hybrid model H1 is shown in Fig. 12. The diagram displays that model achieved a maximum drift ratio of $3.13 \%$ with a maximum load of $41.14 \mathrm{kN}$ in a positive direction. Ultimate capacity was measured to drift ratios in both of the positive and negative directions of $3.13 \%$ and $2.71 \%$, respectively. After completion of the $2.5 \%$ drift ratiocyclic load step, the failure happened at $3 \%$ drift ratio in a negative direction. The FE analysis was promptly stopped without having completed the 3\% drift ratio loop. Failure mode was the cracking of the concrete in the sections of the beam near the face of the column, as seen in Fig. 9c. The concrete elements in this zone were subjected to excessive crushing and cracking. The GFRP rebar remained in the elastic range, while plastic deformation was found in the steel rebar. Due to the plastic deformation of steel reinforcement, a shifting was observed in the cycles less than the case of S1, as seen in Fig. 12. 


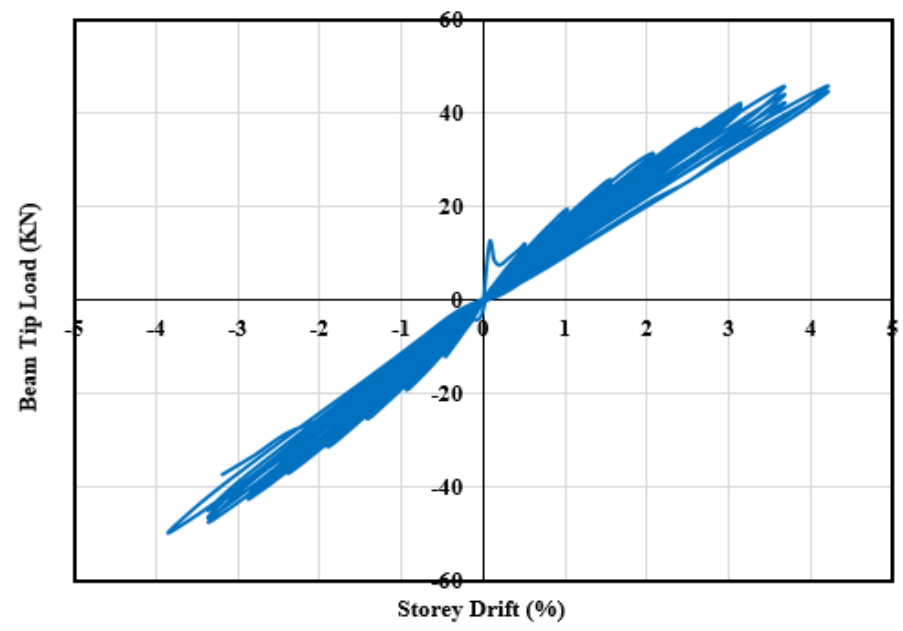

Figure 11: Load-story drift relationship of GFRP model G1.

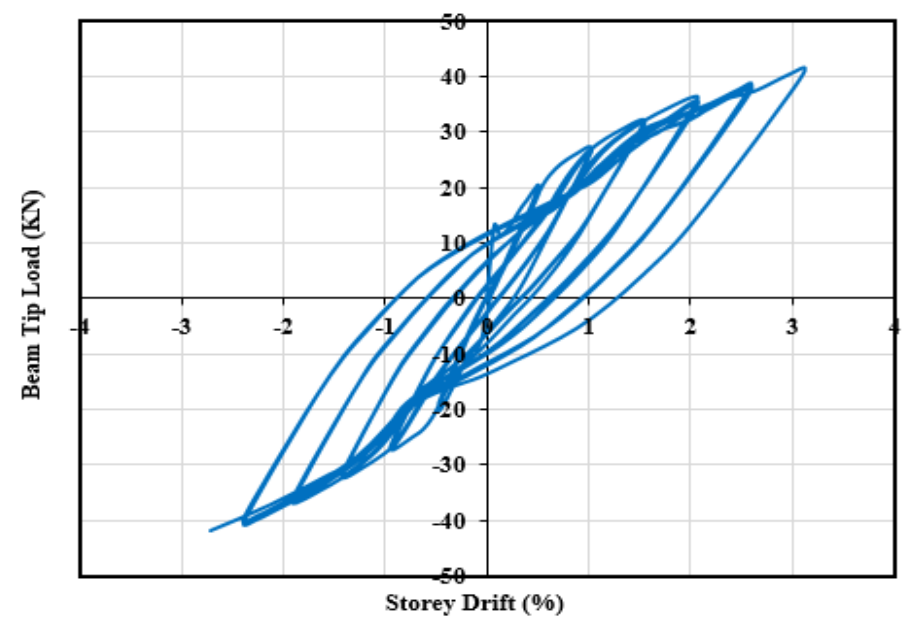

Figure 12: Load-story drift relationship of Hybrid model H1.

\section{Load vs. Story Drift Envelopes}

Comparison of load vs. story drift envelopes for all models is shown in Fig. 13. Envelopes began at similar stiffness; however, once cracking occurs, a distinguished variation between the performance for all models has been shown. Comparison between the three envelopes displayed that the steel-reinforced model has a higher stiffness relative to other models. The total drift of the GFRP model G1 was about 20\% lower than that of the solid model S1 and was 23\% higher than that of the hybrid model $\mathrm{H} 1$ in terms of total drift. The steel model was capable of achieving a much more constant post-yield load capability compared with the other models. Model G1 had an elastic envelope, model S1 had a conventional elastic-plastic envelope, and model $\mathrm{H} 1$ provided a compromise between the performance of the standard steel-reinforced structure and the GFRP-reinforced structure. These results were consistent with previous experimental literature [17,18]. It was concluded in the literature that the GFRP joint displayed very lower plasticity characteristics, and the steel joint showed higher stiffness than the hybrid joint with a higher stiffness than the GFRP joint [17]. In addition, it was concluded that the low modulus of elasticity of the GFRP reinforcement decreased the rigidity of the specimens tested, resulting in lower reactions resulting from the drifts action [18].

\section{Cumulative Dissipated Energy}

An earthquake resistance relies on the structure's capability to dissipate the ground movement-supplied energy.

While the measurement of this energy input by way of the ground movement is complex, and appropriate design must ensure a structure has a higher energy dissipation capacity than demand. 
The cumulative energy dissipated was measured in successive load-displacement cycles by summing the dissipated energy during the reverse cyclic load analysis. The energy dissipated during the cycle is calculated as the area occupied by the hysteretic loop in the load-displacement graph.

Fig. 16 displays cumulative dissipated energy plots vs. story drift for the models analyzed. It can be found that the GFRP reinforced model, i.e., G1 has around 2.5\% of the standard steel-reinforced model S1 capacity of energy dissipation before failure.

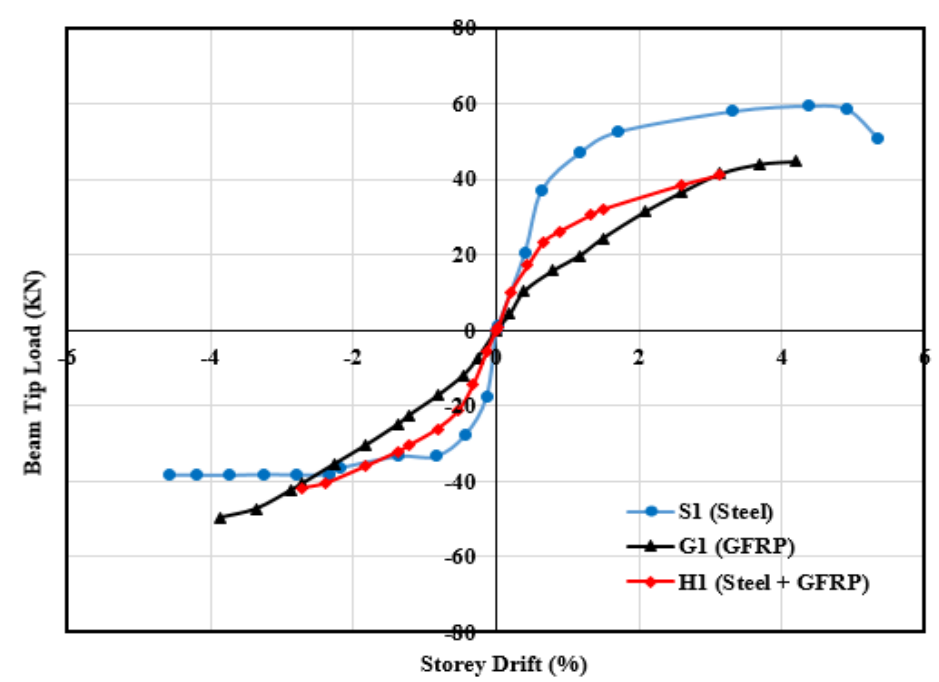

Figure 13: Comparison between load vs. story drift envelopes of all models.

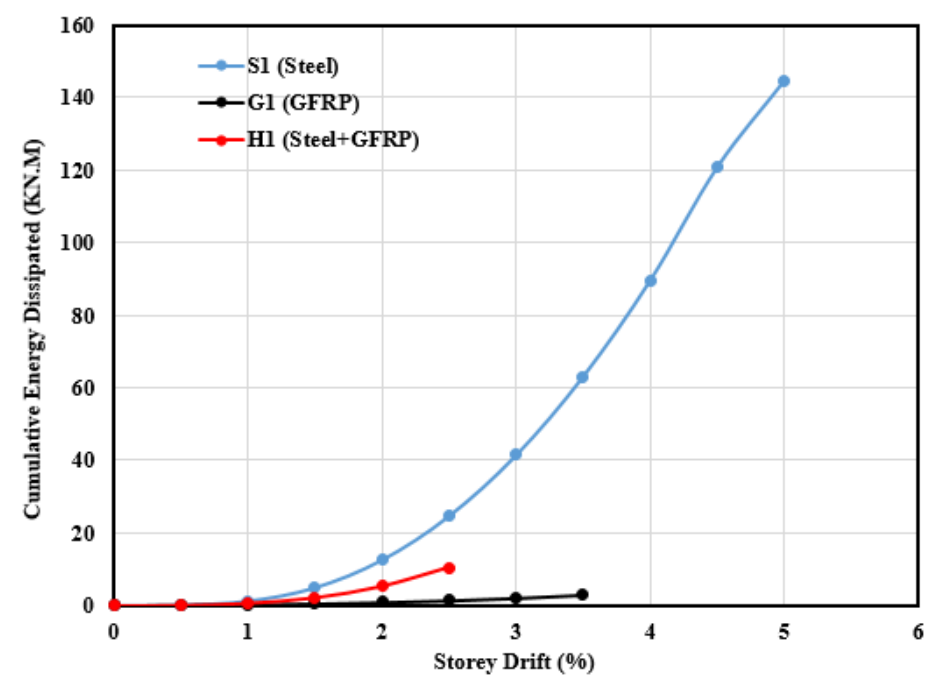

Figure 14: Cumulative energy dissipated for the models.

The Hybrid-reinforced model H1 had about $7.07 \%$ of the standard steel-reinforced model S1 energy's dissipation capacity before failure. The cumulative energy dissipation capacity of the hybrid model H1 was around three times greater at failure than the GFRP model G1. This is apparent in the form of the calculated model individual hysteretic loops, see Figs. 10, 11, and 12 , which are wider for the steel model. The ductility of the steel reinforcement caused the beam to produce greater plastic deformations, thereby increasing the area of each loop.

The amount of damage suffered by the models during failure, as seen in Figs. 9, indicates that while the significant crack in the hinge region of the beam allowed the model to achieve more energy dissipation for the steel model, the GFRP and the hybrid models suffered more although localized destruction. Steel yield has become a significant technique for the dissipation of energy by RC structures, while plastic deformations and friction around concrete cracks typically have a minimizing the dissipation of total energy. These results were consistent with previous experimental literature $[17,18]$. It was 
concluded that specimens with GFRP had poorer energy dissipation compared to steel and hybrid specimens before failure. In addition, the steel-reinforced specimen has absorbed energy much greater than the GFRP and hybrid-reinforced specimens $[17,18]$.

\section{CONCLUSIONS}

7 his research was conducted to investigate the performance of beam-column reinforced joints using hybrid steel/GFRP and GFRP reinforcement in longitudinal reinforcement bars and steel stirrups and compared them to conventional steel-reinforced joints under cyclic reversed load. Based on finite element analysis using ANSYS software and analysis of the results, the following conclusions were drawn:

- GFRP bars may be used as longitudinal reinforcement in beam-column joints exposed to cyclic loading. GFRP bars without any performance degradation can withstand tension-compression cycles.

- The GFRP- beam-column joint demonstrated a declining stiffness compared with the standard beam-column joint enhanced by steel.

- The hybrid GFRP reinforced joint displayed the lowest rigidity compared with the traditional steel-reinforced joint; however, it displayed greater rigidity compared to the GFRP reinforced joint.

- The low elastic modulus of the GFRP reinforcement caused a drop in the total rigidity of this model in operation, resulting in the converging drift ratios being obtained, however at the same time receiving lower forces due to its acting cyclic loading.

- GFRP reinforced joints displayed primarily elastic properties with very poor plasticity characteristics while evaluated under cyclic reversed loading. This resulted in decreased dissipated energy compared with traditional steelreinforced joints.

- The hybrid reinforced model provided a compromise between the performance of the standard steel-reinforced structure and the FRP-reinforced structure.

- A variety of performance requirements, including strength, ductility, durability, stiffness, etc., may be modified to provide a hybrid reinforced frame. The designer may alter the hybrid system's strengthening specification to improve the balance among the design specifications.

\section{REFERENCES}

[1] Said, A.M., Nehdi, M.L. (2004). Performance of Structural Concrete Frames Reinforced With GFRP Grid, 13th World Conf. Earthq. Eng.

[2] Amer, A., Abdel kader, H., Abdel-Razek, L., El-Sisi, A. (2021). Numerical analysis of FRP reinforced frames under cyclic loading, Egypt. J. Eng. Sci. Technol., DOI: 10.21608/eijest.2021.60164.1045.

[3] Benaoum, F., Khelil, F., Benhamena, A. (2020). Numerical analysis of reinforced concrete beams pre-cracked reinforced by composite materials, Frat. Ed Integrita Strutt., 14(54), pp. 282-96, DOI: 10.3221/IGF-ESIS.54.20.

[4] Abedini, M., Akhlaghi, E., Mehrmashhadi, J., Mussa, M.H., Ansari, M., Momeni, T. (2017). Evaluation of Concrete Structures Reinforced with Fiber Reinforced Polymers Bars: A Review, J. Asian Sci. Res., 7(5), pp. 165-175, DOI: 10.18488/journal.2.2017.75.165.175.

[5] Elshazly, F.A., Mustafa, S.A.A., Fawzy, H.M. (2021). Analysis of strengthened short deficient rubberized concrete-filled steel tubular columns, Frat. Ed Integrita Strutt., 15(55), pp. 1-19, DOI: 10.3221/IGF-ESIS.55.01.

[6] Chiozzi, A., Grillanda, N., Milani, G., Tralli, A. (2020). NURBS-based kinematic limit analysis of FRP-reinforced masonry walls with out-of-plane loading, Frat. Ed Integrita Strutt., 14(51), pp. 9-23, DOI: 10.3221/IGF-ESIS.51.02.

[7] El-Emam, H., El-Sisi, A., Reda, R., Seleem, M., Bneni, M. (2020). Effect of concrete cover thickness and main reinforcement ratio on flexural behavior of RC beams strengthened by NSM-GFRP bars, Frat. Ed Integrita Strutt., DOI: $10.3221 /$ IGF-ESIS.52.16.

[8] Mogahed, S.M.M. (2019).Seismic Evaluation of Framed Structures Reinforced with FRP Bars. Zagazig University, 2019.

[9] Davalos, J.F., Chen, Y., Ray, I. (2008). Effect of FRP bar degradation on interface bond with high strength concrete, Cem. Concr. Compos., DOI: 10.1016/j.cemconcomp.2008.05.006.

[10] Alam, M.I., Fawzia, S., Liu, X. (2015). Effect of bond length on the behaviour of CFRP strengthened concrete-filled steel tubes under transverse impact, Compos. Struct., DOI: 10.1016/j.compstruct.2015.06.065. 
[11]Zhang, H., Xu, X. (2018).Finite element analysis of seismic behavior of FRP reinforced concrete frame structure. IOP Conference Series: Earth and Environmental Science.

[12] Shanour, A.S., Mahmoud, A.A., Adam, M.A., Said, M. (2014). Experimental Investigation of Concrete Beams Reinforced With Gfrp Bars, Int. J. Civ. Eng. Technol.

[13] Hasaballa, M., El-Salakawy, E. (2018). Anchorage Performance of GFRP Headed and Bent Bars in Beam-Column Joints Subjected to Seismic Loading, J. Compos. Constr., DOI: 10.1061/(asce)cc.1943-5614.0000888.

[14] Li, S., Guo, S., Yao, Y., Jin, Z., Shi, C., Zhu, D. (2021). The effects of aging in seawater and SWSSC and strain rate on the tensile performance of GFRP/BFRP composites: A critical review, Constr. Build. Mater., 282, pp. 122534, DOI: $10.1016 /$ j.conbuildmat.2021.122534.

[15] Vantadori, S., Carpinteri, A., Głowacka, K., Greco, F., Osiecki, T., Ronchei, C., Zanichelli, A. (2021). Fracture toughness characterisation of a glass fibre-reinforced plastic composite, Fatigue Fract. Eng. Mater. Struct., 44(1), pp. 3-13, DOI: $10.1111 /$ ffe.13309.

[16] Serovaev, G.S., Kosheleva, N.A. (2020). The study of internal structure of woven glass and carbon fiber reinforced composite materials with embedded fiber-optic sensors, Frat. Ed Integrita Strutt., 14(51), pp. 225-235,

DOI: $10.3221 /$ IGF-ESIS.51.18.

[17] Nehdi, M., Said, A. (2005). Performance of RC frames with hybrid reinforcement under reversed cyclic loading, Mater. Struct. Constr., 38(280), pp. 627-37, DOI: 10.1617/14221.

[18] Mady, M., El-Ragaby, A., El-Salakawy, E. (2011). Seismic Behavior of Beam-Column Joints Reinforced with GFRP Bars and Stirrups, J. Compos. Constr., DOI: 10.1061/(asce)cc.1943-5614.0000220.

[19] Ghomi, S.K., El-Salakawy, E. (2018). Seismic Behavior of Exterior GFRP-RC Beam-Column Connections: Analytical Study, J. Compos. Constr., 22(4), pp. 04018022, DOI: 10.1061/(asce)cc.1943-5614.0000858.

[20] Ghomi, S.K., El-Salakawy, E. (2016). Seismic Performance of GFRP-RC Exterior Beam-Column Joints with Lateral Beams, J. Compos. Constr., DOI: 10.1061/(asce)cc.1943-5614.0000582.

[21] Hasaballa, M., El-Salakawy, E. (2016). Shear Capacity of Exterior Beam-Column Joints Reinforced with GFRP Bars and Stirrups, J. Compos. Constr., DOI: 10.1061/(asce)cc.1943-5614.0000609.

[22] ANSYS. (2018). ANSYS Workbench 19.2 Documentation.

[23] Abdulkadir, M.R., Aziz, Z.A., Muhammad, J.H. (2017). Nonlinear finite element analysis of reinforced concrete beams strengthened with externally bonded steel plate using ANSYS, Sulaimania J. Eng. Sci., 4(4), pp. 41-50.

[24] ANSYS. (2013). ANSYS Mechanical APDL Theory Reference, ANSYS Inc.

[25] Alsharari, F., El-Zohairy, A., Salim, H., El-Din El-Sisi, A. (2021). Pre-damage effect on the residual behavior of externally post-tensioned fatigued steel-concrete composite beams, Structures, DOI: 10.1016/j.istruc.2021.02.064.

[26] El-Emam, H., El-Sisi, A., Bneni, M., Ahmad, S.S.E., Sallam, H.E.D.M. (2020). Effects of tensile reinforcing steel ratio and near-surface-mounted bar development length on the structural behavior of strengthened rc beams, Lat. Am. J. Solids Struct., DOI: 10.1590/1679-78255836.

[27] El-Sisi, A.E., Saucier, A., Salim, H.A., Hoemann, J.M. (2019). Experimental and Numerical Evaluation of Reinforced Concrete Walls Retrofit Systems for Blast Mitigation, J. Perform. Constr. Facil., 33(2),

DOI: 10.1061/(ASCE)CF.1943-5509.0001265.

[28] El-Sisi, A.E., Saucier, A., Salim, H.A., Nawar, M. (2017).Experimental and numerical analysis for non-load bearing sandwich wall panels for blast mitigation. Structures Congress 2017: Blast, Impact Loading and Response of Structures - Selected Papers from the Structures Congress 2017.

[29] Hasaballa, M. (2009). Seismic Behaviour of Exterior GFRP-Reinforced Concrete Beam-Column Joints, MSc Thesis, , pp. 197.

[30] Housing and building national search centre. ministry of housing, utilities and urban planning. (2018). Egyptian code for design and constructions concrete structures, cairo.

[31] Housing, M.O.F., Utilities, U., Code, E., Practice, O.F. (2005). Arab Republic of Egypt Ministry of Housing , Utilities and Urban Utilities Egyptian Code of Practice the Use of Fiber Reinforced Polymer (FRP).

[32] ACI Committee 440.1R-06. (2006). Guide for the design and construction of concrete reinforced with FRP bars, Am. Concr. Inst., pp. 44.

[33] Williams, B.K., Banthia, N., Bisby, L., Cheng, R., Fallis, G., Hutchinson, R., Mufti, A., Neale, K.W., Newhook, J., Soudki, K., Wegner, L. (2006). An Introduction to FRP-Reinforced Concrete.

[34] Paknejadi, A.H., Behfarnia, K. (2020). Performance of reinforced self-consolidating concrete beam-column joints with headed bars subjected to pseudo-static cyclic loading, Ain Shams Eng. J., DOI: 10.1016/j.asej.2019.12.008. 